\title{
Obtenção e Caracterização de Carbono Ativado a partir de Resíduos Provenientes de Bandas de Rodagem
}

\author{
Irene T. S. Garcia, Michael R. Nunes, Neftalí L. V. Carreño, Wilhelm M. Wallaw \\ Instituto de Química e Geociências, Universidade Federal de Pelotas \\ Humberto V. Fajardo, Luiz F. D. Probst \\ Departamento de Química, UFSC
}

\begin{abstract}
Resumo: Neste trabalho foi investigada a preparação de carbonos ativados através da pirólise de composições elastoméricas provenientes de resíduos de bandas de rodagem de pneus de automóveis. O material foi processado nas temperaturas de 500, 620 e $700{ }^{\circ} \mathrm{C}$, em atmosfera de $\mathrm{N}_{2}$, utilizando-se o hidróxido de potássio como agente ativador. Os produtos resultantes foram caracterizados pela fisisorção de $\mathrm{N}_{2}$ a $77 \mathrm{~K}$, através de isotermas de Brunauer, Emmet e Teller e por microscopia eletrônica de varredura. Esses carbonos ativados apresentam estruturas típicas de sólidos mesoporosos e a temperatura de pirólise tem grande influência na área específica e distribuição de volume de poros. O carbono ativado obtido a $700{ }^{\circ} \mathrm{C}$ apresentou maior área específica e estrutura porosa compacta. Esse material apresenta melhor desempenho frente à adsorção de azul de metileno, removendo até $1,0 \times 10^{-1} \mathrm{~g}$ de corante por grama de carbono utilizado, em tempos inferiores a $300 \mathrm{~s}$.
\end{abstract}

Palavras-chave: Carbono ativado, pirólise, reciclagem.

\section{Preparation and Characterization of Activated Carbons from Thread of Tire Waste}

Abstract: In this work, the preparation of activated carbons through the pyrolysis of elastomers, arising from car threads of tire waste, was investigated. The material was processed at 500,620 and $700{ }^{\circ} \mathrm{C}$, under $\mathrm{N}_{2}$ atmosphere, by using potassium hydroxide as activating agent. The resulting products were characterized by physisorption of $\mathrm{N}_{2}$ at $77 \mathrm{~K}$, through Brunauer, Emmet and Teller isotherms, and scanning electron microscopy. The carbons obtained display a characteristic structure of mesoporous materials and the pyrolysis temperature has strong influence on the specific area and porous volume distribution. The activated carbon obtained at $700{ }^{\circ} \mathrm{C}$ has high specific area and compact structure. It exhibited high performance for adsorption of methylene blue solution, removing $1.1 \times 10^{-1} \mathrm{~g}$ of the dye per gram of carbon in less than $300 \mathrm{~s}$.

Keywords: Activated carbon, pyrolysis, recycling.

\section{Introdução}

Um grande desafio encontrado atualmente é a destinação dos resíduos poliméricos cuja decomposição, geralmente lenta, representa um sério problema ambiental. Este fato tem sido um desafio, especialmente para a indústria de pneumáticos, onde grandes quantidades de elastômeros são utilizadas na fabricação de pneus cujo desgaste normal leva à perda de uma pequena parte da composição inicial ${ }^{[1]}$. A inutilização do pneu gera desperdício de material de alto valor agregado, além de problemas ambientais. Grande parte dos pneus inservíveis tem como destino aterros e lixões, sendo que apenas $34,5 \%$ são reutilizados ${ }^{[1]}$. Esse índice mostra a necessidade de tecnologias de reciclagem dos resíduos gerados na indústria de pneumáticos. A resolução ${ }^{\circ}$ 258 de 26/08/99, do Conselho Nacional do Meio Ambiente (CONAMA), passou a exigir das empresas (produtoras, revendedoras e usuárias) a reciclagem na proporção de $1 \mathrm{em}$ 4 pneus fabricados em 2002, $2 \mathrm{em} 4 \mathrm{em} \mathrm{2003,} 3 \mathrm{em} 4 \mathrm{em}$
2004, 4 em 4 em 2005 e 5 em 4 em 2006, visando assim reprocessar o estoque de pneus usados no passado.

Os elastômeros, uma vez submetidos ao processo de vulcanização, não podem ser reprocessados pela simples aplicação de calor e pressão. Os processos de recapagem de pneus representam uma forma de aumentar a vida útil das carcaças.

Adhikari et al. ${ }^{[2]}$ mencionam processos de reciclagem de borracha vulcanizada, como a incorporação em massa asfáltica e processos físicos que incluem a recuperação mecânica, termo-mecânica, criogênica e recuperação através de técnicas de ultra-som e microondas. São apresentados também processos químicos de recuperação utilizando agentes inorgânicos e o uso de microorganismos. A recuperação criogênica para obtenção de material na forma de pó é apresentada em detalhes no trabalho de Smith e colaboradores ${ }^{[3]}$.

A queima para geração de energia também pode ser feita com pneus inteiros, mecanicamente processados, em forma de lascas ou em pó, podendo ser adicionados ao carvão como suplemento energético ${ }^{[2,4,5]}$.

Autor para correspondência: Irene T. S. Garcia, Instituto de Química e Geociências, Universidade Federal de Pelotas, Capão do Leão s/n, CEP: 96010-900, Pelotas, RS, Brasil.E-mail: irene@ufpel.edu.br 
Entre os processos de reaproveitamento que envolvem a alteração da estrutura química dos pneus podem ser citados a pirólise, extração supercrítica de óleos para a produção de combustíveis e a obtenção de carbono ativado ${ }^{[6,7]}$. Os gases e óleos resultantes da pirólise de pneus foram caracterizados por Rodriguez et al., sendo os primeiros constituídos de hidrocarbonetos de um a quatro átomos de carbonos predominantemente. Outra parte é constituída de $\mathrm{CO}, \mathrm{CO}_{2}$ e $\mathrm{H}_{2} \mathrm{~S}$. Os óleos apresentam-se como misturas complexas de compostos orgânicos com cadeias de cinco a vinte átomos de carbono, com grande proporção de aromáticos, além de compostos contendo enxofre e nitrogênio ${ }^{[8]}$.

No que se refere à produção de carbono, diferentes processos levam à produção de materiais com propriedades específicas. Diferentes tipos de carbono tais como amorfo hidrogenado, polimérico, fulerenos com diferentes números de carbonos, nanotubos de parede simples e paredes múltiplas ${ }^{[9-12]}$ têm sido sintetizados e caracterizados. A produção de carbonos ativados a partir de pneus pode ser realizada pela pirólise sob fluxo de um gás inerte, podendo ser utilizados métodos de ativação química, como a ativação com solução de ácido sulfúrico e ácido nítrico ${ }^{[13]}$, agentes ativadores em estado sólido $^{[14]}$ ou pirólise sem o uso do agente ativador ${ }^{[15]}$. Neste caso é necessária posterior ativação da superfície através de dióxido de carbono e vapor d'água ${ }^{[15]}$. Aspectos envolvendo a produção de carbonos ativados a partir de pneus tais como efeitos de temperatura, ativação química e física, além da modelagem cinética de reações de pirólise através de métodos termogravimétricos, são revisados por Mui et al ${ }^{[16]}$.

O carbono ativado pode ser utilizado na adsorção de contaminantes orgânicos como compostos organoclorados, aromáticos e corantes provientes da indústria têxtil, apresentando também aplicações como catalisador em síntese orgânica e recuperação de solventes ${ }^{[17,18]}$.

Para que a produção e o desempenho dos carbonos ativados obtidos a partir de pneus possam ser otimizados, é importante levar em conta as características de cada parte que os compõem, aspecto este ainda a ser explorado. Neste trabalho foi investigada a obtenção de carbonos ativados a partir da pirólise de aparas de bandas de rodagem. Essa parte do pneu foi escolhida por não apresentar inconvenientes para o reaproveitamento, como a presença de aço ou fibras misturados à borracha. Foi utilizado hidróxido de potássio como agente ativador e investigada a pirólise em diferentes temperaturas, de acordo com estudo prévio de reaproveitamento de outros resíduos ${ }^{[6]}$. A caracterização das estruturas obtidas desses carbonos ocorreu por Microscopia Eletrônica de Varredura $(\mathrm{MEV})$ e através de adsorção e dessorção de Nitrogênio a $77 \mathrm{~K}$. Também foi testado o desempenho de adsorção frente a um corante orgânico típico, o azul de metileno.

\section{Experimental}

A matéria-prima utilizada consistiu de partículas de borracha vulcanizada menores que $300 \mu \mathrm{m}$ trituradas, oriundas de bandas de rodagem de automóveis de passeio. Essas bandas de rodagem são constituídas de $13,0 \%$ de poli-cis-isopreno, $16,8 \%$ de copolímero de estireno-butadieno, $21,8 \%$ de poli-cis-butadieno, $29,5 \%$ de negro de fumo, $13,3 \%$ de óleo aromático, $0,5 \%$ de ácido esteárico, 1,0\% de enxofre, $2 \%$ de óxido de zinco, $0,5 \%$ de acelerador de vulcanização e $1,5 \%$ de antioxidante.

O material foi misturado na proporção de 1:1 em massa com KOH no estado sólido e mantido sob agitação mecânica durante 30 minutos. A mistura, higroscópica, foi seca em estufa a $110^{\circ} \mathrm{C}$ durante 12 horas e disposta em substrato de aço inox. O sistema foi pirolisado em forno tubular termoprogramado, como esquematizado na Figura 1, em temperaturas máximas de 500, 620 e $700{ }^{\circ} \mathrm{C}$ por duas horas, sob fluxo de $\mathrm{N}_{2}$ de $130 \mathrm{~cm}^{3} \cdot \mathrm{min}^{-1}$. As velocidades de aquecimento e resfriamento foram de $5{ }^{\circ} \mathrm{C} \cdot \mathrm{min}^{-1}$. Os materiais sólidos resultantes foram tratados com ácido clorídrico $1 \mathrm{M}$, sob agitação, por 2 horas. $\mathrm{O} \mathrm{HCl}$ remove o enxofre utilizado na vucanização da borracha que, durante o processo de pirólise em meio rico em carbono, foi convertido a sulfeto. $\mathrm{O}$ tratamento com $\mathrm{HCl}$ permite também a remoção do $\mathrm{ZnO}$ proveniente da composição elastomérica, onde é utilizado como agente ativador de vulcanização. A remoção de enxofre e de zinco foi monitorada por testes qualitativos utilizando-se soluções de acetato de chumbo 0,5 mol.L $\mathrm{L}^{-1}$ e ferrocianeto de potássio $0,1 \mathrm{~mol} . \mathrm{L}^{-1}$, respectivamente. A seguir, os carbonos ativados foram lavados com água destilada quente e, após, com água destilada fria até $\mathrm{pH} 7,0$ e secos em estufa por 2 horas a $110^{\circ} \mathrm{C}$. A perda de massa foi calculada levando-se em conta a massa da mistura original e do material pirolisado.

As isotermas de adsorção-desorção de $\mathrm{N}_{2}$ a $77 \mathrm{~K}$ foram realizadas em equipamento Autosorb-1C da Quantachome Instruments. As isotermas foram obtidas para pressões relativas $\left(\mathrm{P} / \mathrm{P}_{0}\right)$ situadas entre 0,1 e 1 .

As estruturas dos carbonos ativados obtidos foram analisadas através de microscopia eletrônica de varredura em um equipamento Zeis DSM 940A.

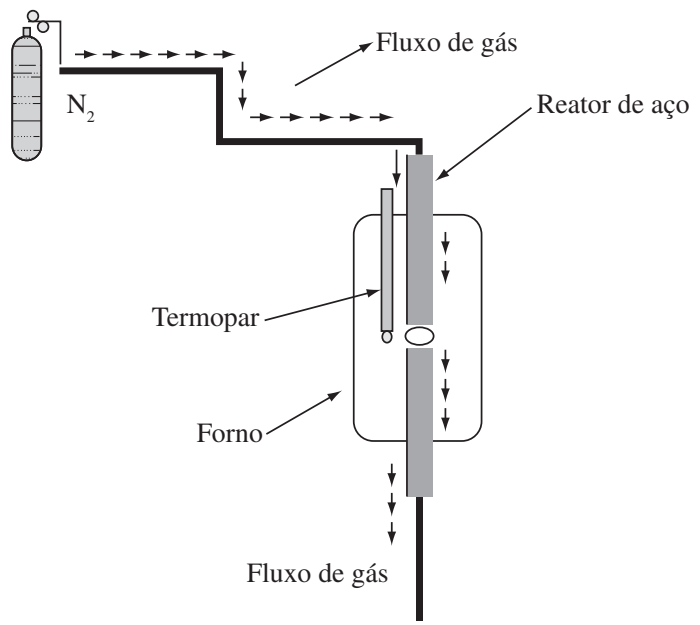

Figura 1. Esquema do forno tubular termoprogramável utilizado na obtenção de carbono ativado. 
A capacidade adsortiva dos carbonos ativados foi avaliada através de medidas de absorbância de uma solução com concentração inicial de $6,610^{-4} \mathrm{~mol} . \mathrm{L}^{-1}$ de corante azul de metileno a $590 \mathrm{~nm}$. Os ensaios, feitos em triplicata, foram realizados utilizando-se $2 \times 10^{-3} \mathrm{~g}$ de carbono ativado para cada $\mathrm{mL}$ da solução de corante, deixados sob agitação durante 1 hora. A adsorção foi caracterizada em pH 7,0 a $25^{\circ} \mathrm{C}$.

$\mathrm{O}$ acompanhamento da remoção do corante em função do tempo foi feito com o material que apresentou maior capacidade de retenção do azul de metileno no ensaio anterior, utilizando-se as mesmas condições experimentais.

\section{Resultados e Discussão}

A perda de voláteis e de produtos de degradação, calculada através da diferença entre a massa do material original e o produto de pirólise, foi de $25 \pm 5,29 \pm 5,24 \pm 5 \%$ para as temperaturas de 500,620 e $700^{\circ} \mathrm{C}$, respectivamente. A temperatura de pirólise não tem influência significativa na perda de voláteis e os baixos valores encontrados podem ser explicados pela presença do agente ativador $\mathrm{KOH}$ que inibe a liberação de matéria orgânica volátil convertendo-a em carbono fixo ${ }^{[7]}$.

As isotermas de adsorção-dessorção para os carbonos ativados estabelecem a relação entre a quantidade molar de $\mathrm{N}_{2}$ adsorvida ou dessorvida pelo material em função da pressão relativa $\mathrm{P} / \mathrm{P}_{0}$, onde $\mathrm{P}$ é a pressão de trabalho e $\mathrm{P}_{0}$ a pressão de vapor do $\mathrm{N}_{2}$ na temperatura de $77 \mathrm{~K}$. As Figuras $2 \mathrm{a}$ e b mostram isotermas típicas de materiais com poros razoavelmente grandes, nos quais o processo de adsorção é similar ao processo de dessorção. Essas isotermas são características de poros com formatos cônicos ou de canais em "v", que dão origem a isotermas sem histerese. Já a Figura $2 c$, referente à amostra pirolisada a $700{ }^{\circ} \mathrm{C}$, apresenta isotermas cujo fenômeno de histerese está presente e relacionado com diferenças entre os processos de adsorção e dessorção. As curvas sugerem que as amostras a 500 e $620{ }^{\circ} \mathrm{C}$ apresentam poros mais largos e rasos que a amostra obtida a $700{ }^{\circ} \mathrm{C}$. Na Tabela 1 são apresentados os valores de área específica, calculados através do modelo BET de multicamada, para a composição de borracha e para os carbonos ativados preparados nas diferentes temperaturas. A área específica obtida é diretamente proporcional à temperatura de pirólise.

Tabela 1. Área específica, volume de poros e diâmetro médio de poro para os carbonos ativados

\begin{tabular}{|c|c|c|c|}
\hline $\begin{array}{l}\text { Temperatura } \\
\text { máxima de } \\
\text { pirólise }\left({ }^{\circ} \mathrm{C}\right)\end{array}$ & $\begin{array}{c}\text { Área } \\
\text { específica }^{(a)} \\
\left(\mathbf{m}^{2} / \mathbf{g}\right)\end{array}$ & $\begin{array}{l}\text { Volume } \\
\operatorname{poros}^{(\mathbf{b})} \\
\left(\mathrm{cm}^{3} \cdot \mathrm{g}^{-1}\right) \\
\end{array}$ & $\begin{array}{l}\text { Diâmetro } \\
\text { médio de } \\
\text { poro }(\mathbf{n m}) \\
\end{array}$ \\
\hline $\begin{array}{l}\text { Borracha sem } \\
\text { tratamento }\end{array}$ & 9,4 & - & - \\
\hline 500 & 49,6 & $8,70 \times 10^{-2}$ & 3,67 \\
\hline 620 & 327,3 & $6,21 \times 10^{-1}$ & 3,45 \\
\hline 700 & 501,8 & $3,11 \times 10^{-1}$ & 2,79 \\
\hline
\end{tabular}

${ }^{(a)}$ calculada pelo método BET em multicamadas; $\mathrm{e}^{(\mathrm{b})}$ calculado pelo método BJH.

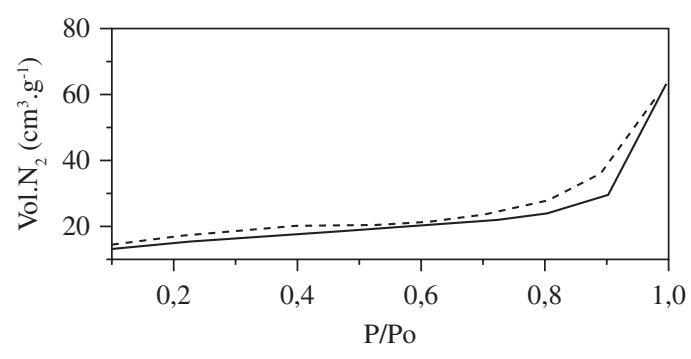

(a)

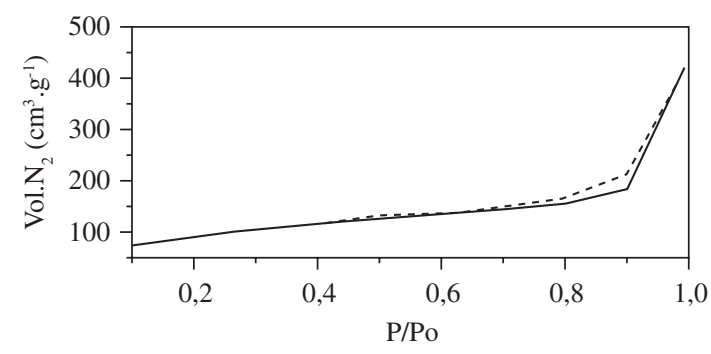

(b)

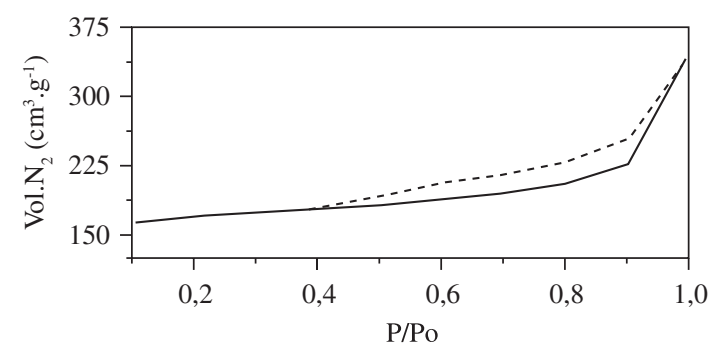

(c)

Figura 2. Comportamento de adsorção de $\mathrm{N}_{2}$ a $77 \mathrm{~K}$ ( linha contínua) e dessorção (linha tracejada) das amostras de carbono ativado obtidas por pirólise nas temperaturas de: a) $500{ }^{\circ} \mathrm{C}$; e b) $620^{\circ} \mathrm{C}$; e c) $700{ }^{\circ} \mathrm{C}$.

As curvas de distribuição de tamanhos de poros são importantes para o estudo da estrutura porosa, estando relacionadas à área total do sólido e à homogeneidade do material obtido. Entre os métodos que podem ser usados para a determinação da distribuição de tamanho de poros ${ }^{[19,20]}$, o método de Barret, Joyner e Halenda $(\mathrm{BJH})^{[20]}$ é o mais indicado para a caracterização de sólidos microporosos e mesoporosos com diâmetro de poro de até $400 \AA$.

O método BJH utiliza a equação de Kelvin $^{[19]}$ e assume o esvaziamento progressivo dos poros com o decréscimo da pressão. Neste trabalho o método BJH foi aplicado ao ramo de adsorção da isoterma. As curvas de distribuição de tamanhos de poros são apresentadas na Figura 3, onde $d_{\mathrm{p}}$ é a variação de volume de poros quando o diâmetro de um poro cilíndrico varia de $\mathrm{D}_{\mathrm{p}}$ a $\mathrm{D}_{\mathrm{p}} \pm \mathrm{dD}_{\mathrm{p}}$. A altura da curva em qualquer ponto ao longo de $\mathrm{D}_{\mathrm{p}}$ reflete não apenas o volume de poro naquele ponto, mas também a pressão na qual o gás foi inserido nos poros. As amostras obtidas a 620 e $700{ }^{\circ} \mathrm{C}$ apresentam maior capacidade de adsorção que o carbono obtido a $500{ }^{\circ} \mathrm{C}$. Os valores de volume de poros calculados estão presentes na Tabela 1 , assim como o diâmetro médio de poros. A amostra obtida a $500{ }^{\circ} \mathrm{C}$ apresenta o menor volume e 
distribuição no tamanho de poros e apresenta também uma pequena área específica.

A microscopia eletrônica de varredura permite observar a morfologia dos poros das amostras. As Figuras 4a e b mostram as fotomicrografias dos carbonos ativados obtidos nas temperaturas de 500 e $700{ }^{\circ} \mathrm{C}$, respectivamente. As fotomi-

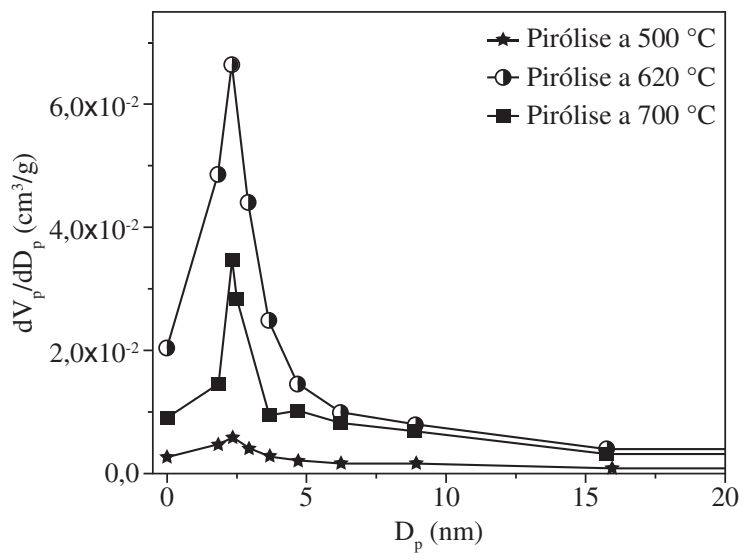

Figura 3. Distribuição de tamanho de poros dos carbonos ativados obtidos nas temperaturas de 500,620 e $700{ }^{\circ} \mathrm{C}$. $\mathrm{V}_{\mathrm{p}}$ é volume e $\mathrm{D}_{\mathrm{p}}$ é o diâmetro de poro.

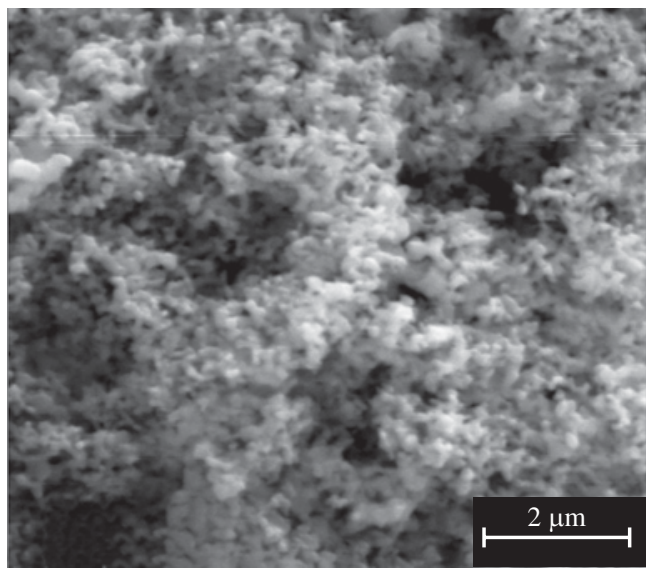

(a)

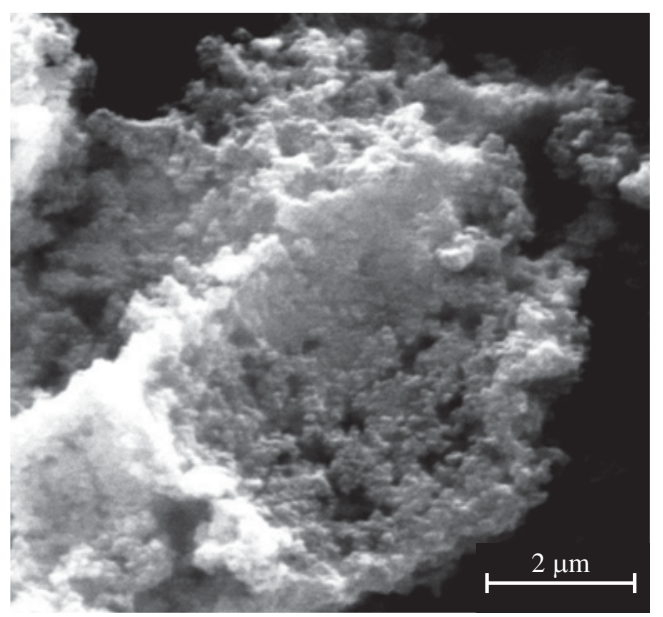

(b)

Figura 4. Fotomicrografias com aumento de 10.000 vezes dos carbonos ativados obtidos: a) $500{ }^{\circ} \mathrm{C}$; e b) $700{ }^{\circ} \mathrm{C}$. crografias, com aumento de 10000 vezes, confirmam a estrutura mesoporosa dos carbonos obtidos. A amostra de $500{ }^{\circ} \mathrm{C}$ apresenta-se na forma de um aglomerado de pequenas partículas com poros irregulares. A amostra obtida na temperatura de $700{ }^{\circ} \mathrm{C}$ apresenta estrutura mais compacta e homogênea.

A remoção de corante azul de metileno a $25^{\circ} \mathrm{C}$ pelos carbonos ativados obtidos, para tempos fixos de contato entre solução de corante e carbono ativado de 1 hora, encontra-se na Tabela 2. A temperatura de pirólise tem influência na qualidade do carbono ativado obtido frente as suas características adsortivas. $\mathrm{O}$ carbono ativado obtido a $700{ }^{\circ} \mathrm{C}$ apresenta excelente desempenho na remoção do corante. Esses resultados concordam com os resultados da Tabela 1 .

Para caracterizar o tempo necessário para uma remoção eficiente do corante pelo carbono ativado, foram realizados ensaios de adsorção com a amostra obtida a $700^{\circ} \mathrm{C}$, que apresentou melhor desempenho do ensaio anterior. A Figura 5 apresenta o comportamento de adsorção em função do tempo para esse carbono e para um carbono ativado comercial. A remoção quase completa do corante ocorre em tempos inferiores a 300 segundos e é semelhante ao carbono ativado comercial analisado. Os carbonos obtidos a partir das bandas de rodagem de pneus, sob ativação com $\mathrm{KOH}$, apresentam tempos de adsorção inferiores aos dos carbonos obtidos a partir de fibra de casca de coco para soluções de azul de metileno com concentração seis vezes menor ${ }^{[9]}$. Esses tempos de adsorção menores podem ser explicados pela disponibilidade da estrutura do carbono ativado à migração das moléculas do corante para sítios ativos acessíveis às mesmas.

Tabela 2. Remoção de azul de metileno de uma solução $6,610^{-4} \mathrm{~mol} \cdot \mathrm{L}^{-1} \mathrm{em}$ $\mathrm{pH} 7,0$ a $25^{\circ} \mathrm{C}$ pelos dos carbonos ativados obtidos com tempo de contato de uma hora.

\begin{tabular}{cc}
\hline $\begin{array}{c}\text { Temperatura máxima } \\
\text { de pirólise }\left({ }^{\circ} \mathbf{C}\right)\end{array}$ & $\begin{array}{c}\text { Azul de metileno } \\
\text { removido }(\%)\end{array}$ \\
\hline Borracha sem tratamento & - \\
500 & $31 \pm 2$ \\
620 & $87 \pm 2$ \\
700 & $99 \pm 2$ \\
\hline
\end{tabular}

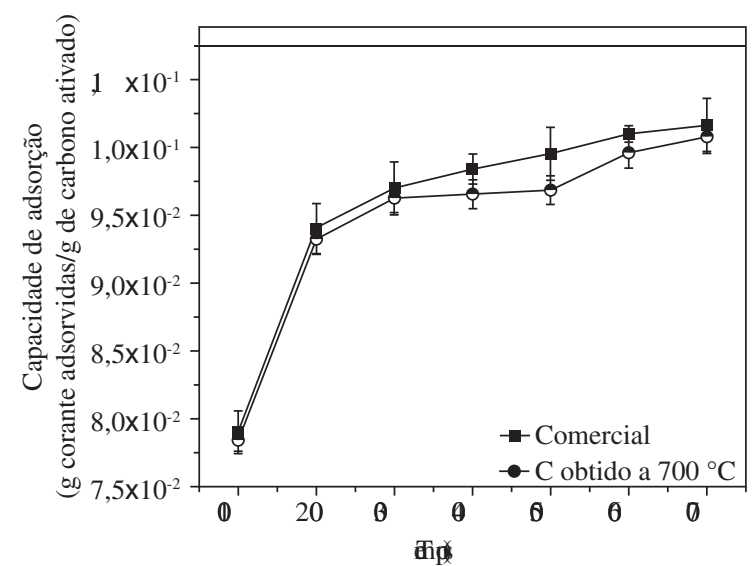

Figura 5. Capacidade de adsorção de solução de azul de metileno na temperatura de $25^{\circ} \mathrm{C}$, em função do tempo para o carbono ativado obtido na temperatura de $700{ }^{\circ} \mathrm{C}$ e para um carbono ativado comercial. 


\section{Conclusões}

O tratamento de aparas de borracha proveniente de bandas de rodagem tendo $\mathrm{KOH}$ como agente de ativação foi estudado em três diferentes temperaturas.

Ocorreu pequena perda de voláteis e de produtos de degradação durante a pirólise, não sendo significativa essa variação com a temperatura. A área específica dos carbonos obtidos é diretamente proporcional à temperatura de pirólise e todos os carbonos ativados obtidos podem ser classificados como mesoporosos. As estruturas obtidas apresentam-se como um aglomerado de pequenas partículas, para temperaturas baixas de pirólise, e estrutura porosa homogênea, quando os carbonos são obtidos em temperaturas mais elevadas.

$\mathrm{O}$ material pirolisado a $700{ }^{\circ} \mathrm{C}$ apresentou maior desempenho frente à adsorção de azul de metileno, correspondendo à retirada de 0,1 grama de corante por grama de carbono ativado. $\mathrm{O}$ tempo necessário para o equilíbrio ser atingido foi inferior a $300 \mathrm{~s}$. Esse tempo de remoção é semelhante ao obtido com carbono ativado comercial e inferior aos tempos de remoção apresentados por carbonos obtidos de outros resíduos ${ }^{[9]}$.

A pirólise de resíduos obtidos a partir de bandas de rodagem constitui um meio eficiente para obtenção de carbono ativado com elevada área específica e excelente desempenho frente à remoção de um corante orgânico típico.

\section{Agradecimentos}

Esse trabalho foi desenvolvido com apoio financeiro dos seguintes órgãos: FAPERGS/PROADE, CNPq/CT-PETRO e $\mathrm{CNPq} / \mathrm{PIBIC}$.

\section{Referências Bibliográficas}

1. Caponero, J.; Levendis, Y. \& Tenório, J. S. - “Análise Crítica das Tecnologias Aplicadas a Destinação Final de Pneus", in: Anais do 55 Congresso Anual da Associação Brasileira de Metalurgia Materiais, p. 2593, Rio de Janeiro - RJ, (2000).

2. Adhikari, B.; De, D. \& Maiti, S. - Prog. Polym. Sci., 25, p.909 (2000).

3. Smith, A. P.; Adeb, H. Kocha, C. C. \& Spontak, R. J. Polymer, 42, p.4453 (2001).
4. Pakdel, H.; Pantea, D. M. \& Roy, C. - J. Anal. Appl. Pyrolysis, 57, p.91(2001).

5. Goulart, E. A.; Mariatoni, C. A. \& Sanchez, C. G. - Polímeros, 9, p.123 (1999).

6. Ahmadpour, A. \& Do, D. D. - Carbon, 34, p.471 (1996).

7. Hayashi, J.; Kazehaya, A.; Muroyama, K. \& Watkinson, A. P. - Carbon, 38, p.1873 (2000).

8. Rodriguez, I.; Loresgoiti, M. F.,; Cabrero, M. A.; Torres, A.; Chomón, M. J. \& Cabalero, B. - Fuel Process.Technol., 72, p.9 (2001).

9. Macedo, J. S.; Almeida, L. E.; Vieira, E. F.; Cestari, A. R.; Gimenez, I. F.; Carreño, N. L. V. \& Barreto, L. S. J. Colloid Interface Sci., 298, p.515 (2006).

10. Py, X.; Guillot, A. \& Cagnon, B. - Carbon 42, p.1743 (2004).

11. Baptista, D. L.; Garcia, I. T. S. \& Zawislak, F. C. - Nucl. Instrum. Methods Phys. Res., Sect. B - 219, p.864 (2004).

12. Garcia, I. T. S. ; Zawislak, F. C. \& Samios, D. - Appl. Surf. Sci. 228, p. 63 (2004).

13. Manchón, V.; Garcia, M.; Gisbert, N.; Gonzales, F. \& Gomez Serrano - Microporous Mesoporous Mater., 67, p.35 (2004).

14. Teng, H.; Lin, Y. U. \& Hsu L. Y. - J. Air Waste Manage Ass., 50, p.1940 (2000).

15. González, J.; Encinar, J.; García, C.; Sabio, E.; Ramiro, A.; Canito, J. \& Gañan, J. - Appl. Surf. Sci., 252, p.5999 (2006).

16. Mui, E. L. K.; Ko, D. \& Mckay, G. - Carbon, 42, p. 2789 (2004).

17. Tanthapanichakoon, W.; Ariyadejwanich, P.; Japthong, P. \& Nakagawa, K. - Water Res., 39, p.1347 (2005).

18. Ariyadejwanich, A.; Tantapanichakoon, W.; Nakagawa, K.; Mukai, S. R. \& Tomon, H. - Carbon, 41, p.157 (2003).

19. Teixeira, V. G.; Coutinho, F. M. B. \& Gomes, A. S. Quim. Nova, 24, p.808 (2001).

20. Barrett, E. P.; Joyner, L. G. \& Halenda, P. P. - J. Am. Chem. Soc., 73, p.373 (1951).

Enviado: 26/02/07

Reenviado: 10/04/07

Aceito: 16/04/07 